\title{
The COVID-19 Outbreak and National Accounts - Some Remarks on Selected Aspects
}

\author{
Josef Richter \\ Previously \\ Austrian Economic Chamber, University of Innsbruck, University of Linz
}

\begin{abstract}
The outbreak of COVID-19 has had severe impacts on the ability of statistical authorities to compile national accounts data in the usual way. There is a lack of usually available primary information and a need to deal with a number of new policy measures taken in the context of the COVID-19 crisis. At the same time, the new situation may be an incentive to reconsider some of the basic concepts of national accounts and the way these concepts are operationalised.

The emphasis of this contribution is laid on the concepts of production and of volume measurement of production. Two examples were chosen: a) the implications of changes in the travel habits, in particular of holders of season tickets and b) the reduced number of spectators allowed in theatrical and opera performances. As shown, the methodological alternatives for dealing with these changes offered in the European legislation might lead to quite different results. The two examples reveal that similar situations are treated rather differently.

The examples also indicate that the methodological alternatives pursue different concepts of production. In order to make adequate use of national accounts, empirical economists need to be well informed about the definitions and processes that lead to the data under usual conditions and in particular under exceptional circumstances such as the COVID-19 crisis.
\end{abstract}

Keywords: national accounts, concepts of production, volume and price measurement, COVID19.

\section{Introduction}

Extraordinary events force us to stop for a moment and reflect on the core of the concepts behind the established routines when carrying out established procedures for compiling national accounts. The users of national accounts results should question whether the standard approaches lead to results that correspond with their theoretical ideas even under special circumstances. In both cases, it is necessary to check the assumptions behind the selected procedures and to consider the consequences for the interpretation and for further use of resulting data.

For example, the consequences of the Chernobyl reactor disaster were the motivation for 
Franz (1988) to rethink such elementary questions as When is production given? and to discuss alternative treatment options in national accounts.

The COVID-19 outbreak, its economic consequences and the various measures taken in its context should also be seen as an occasion to consider which theoretical ideas are actually to be operationalised in national accounts. To put it differently and more simply: what do we actually want to measure? Since national accounts are a multi-purpose system, it is also necessary to define a hierarchy of functions that are to be fulfilled.

The list of new phenomena to be dealt with in national accounts in times of a pandemic is long. The following are but a few examples:

- Regulations concerning short-time work

- Granting of turnover remuneration and fixed cost remuneration

- Payments under the hardship fund

- Home-schooling at all levels of the educational system

- Working from home; because the durable goods (PC equipment) and premises used are not part of the capital stock of national accounts, the energy consumption - if not refunded by the employer - is private consumption.

In response to these challenges, Eurostat and national statistical authorities have already elaborated some guidelines and notes on how to address the methodological issues triggered by these changes. The new guidelines and methodological notes in the context of the COVID19 crisis are made available by Eurostat in a methodological corner (Eurostat 2021) and will be regularly updated as new guidelines are developed.

In addition, some conceptual issues that are and have been well known, but tended to be neglected because of their rather small magnitude, acquire new relevance and demand attention.

In this paper, two special situations in the production and use of specific services triggered by the outbreak of COVID-19 and their treatment in national accounts will be examined in more detail. The two rather insignificant examples were chosen because in both cases, questions arise about the concept of production and problems become apparent in the valuation of production at constant prices, in volume measurement.

As far as the production and use of services are concerned, the two examples presented are rather similar. However, the method of payment for these services differs, as does their treatment in national accounts. In the following, national accounts as they are to be compiled according to the European System of Accounts 2010 (Eurostat 2013) will be used as a starting point. Therefore, in the subsequent two sections, some principles of the system will briefly be recalled and characterised in more detail. Some of the methodological notes published by Eurostat (2021) are dealing with national accounts, but none of them are directly related to the examples discussed in this contribution.

\section{Production in the system of national accounts}

In the system of national accounts, production is defined as "an activity carried out under the control, responsibility and management of an institutional unit that uses inputs of labour, capital and goods and services to produce outputs of goods and services" (ESA 2010, 3.07 the European System of Accounts 2010 always cited as ESA 2010 with indication of Chapter number). Production includes the production of all individual or collective goods and services that are supplied to units other than their producers and - in a restricted and well-defined manner - the own-account production of goods for own final consumption or gross fixed capital formation (ESA 2010 3.08). 
Three types of output are distinguished in the ESA 2010, namely market output, output produced for own final use and non-market output. Market output and output produced for own final use are valued at basic prices, whereas total output of non-market producers is valued by summing up the costs of production (ESA 2010 3.16). "Market output consists of output that is disposed of on the market or intended to be disposed of on the market" (ESA 20103.17 ).

It needs to be underlined that in the area of market production, the economic concept of production dominates in national accounts. If one disregards (temporary) production for stock and production for own consumption, only those goods and services that could be marketed are considered production. Produced food that did not find a buyer and has gone bad is not treated as production, nor is technical equipment or fashion items for which no buyers could be found. The market serves as a corrective to what is counted as production.

In a technical understanding of production (the technical concept of production), on the other hand, production already exists as soon as a production process is completed and a product that meets the requirements defined a priori is available. This is independent of whether the product finds buyers or not.

Although national accounts are committed to the economic concept of production in the area of market production, data (e.g. in units of quantity) that reflects a more technical concept of production must always be used when operationalising the basic concepts.

The key variable output is defined as the sum of products created during the accounting period (ESA 2010 3.14). A basic principle of the system is that all flows and stocks, with the exception of some variables concerning population and labour, are shown in monetary terms. "Flows and stocks shall be measured according to their exchange value, i.e. the value at which flows and stocks are in fact, or could be, exchanged for cash. Market prices are, thus, the ESA's reference for valuation" (ESA 2010 1.94). "When no market prices for analogous products are available, for instance in the case of non-market services produced by government, valuation is made by summing production costs" (ESA 2010 1.95).

For the non-market sector, the corrective of the market is missing: the convention is that the non-market services of government must always be considered production; production is equated with production costs.

\section{Principles of volume measurement according to the ESA}

In national accounts, flows and stocks are measured in monetary units. The monetary unit is the common denominator used to value the highly diverse transactions recorded in the system of accounts and to calculate meaningful balances. The observed prices - characteristics of goods or, even more precisely, of goods in transactions - serve as units of account, as numeraire.

"On a conceptual level, the use of an accounting framework covering the entire economic system requires the prices and physical units for the different products and flows in the system to be specified consistently. In a framework of this type, the price and volume concepts for a given group of products are defined identically in both resources and uses" (ESA 2010 10.04).

On a statistical level, the use of the economic accounts framework imposes accounting constraints which must be respected at both current prices and in volume terms. The creation of an integrated system of price and volume indices in the context of a system of economic accounts provides the national accountant with extra checks (ESA 2010 10.04).

National accounts at current price account is based on a valuation of the individual transactions with the respective prices of the reporting year. This is already done in the accounting systems of the individual enterprises. national accounts take the aggregates which were formed at the lowest level and aggregate them further. This is a bottom-up approach.

From a conceptual point of view, if the primary objective is to record the production processes, 
the calculation at constant prices - analogous to the calculation at current prices - should include a valuation at the level of the individual transactions at the prices of the base year. Such an approach is not (or rarely) feasible for practical reasons, but it would correspond to the theoretical model. This approach is therefore also referred to as the basic model in the following.

An acceptable approximation for many purposes can be achieved if the valuation at base year prices can be based on the level of narrowly defined groups of goods and then further aggregated. At a higher level of aggregation, the results at constant prices then also reflect the changed composition of the bundle of goods, the product-mix effect. The deflators to be derived in comparison to the results of the calculation at current prices reflect price changes and product-mix changes when a bottom-up approach is employed.

In a set consisting of homogeneous products between two periods, each of the homogeneous products is valued by applying the prices of the base period to the quantities of the current period. At the level of the set of products, aggregation leads to the notion of volume. In the calculation of the volume the result depends on the price structure of the base year (ESA 2010 10.20).

A shift over time to the higher-priced homogeneous good in the aggregate with constant quantitative consumption in the aggregate is consistently shown as a positive change in volume.

Any top-down approach, as repeatedly addressed in the ESA, must be distinguished from this approximation of the theoretical model: "Transaction values have to be decomposed into price and volume components" (European Commission 1998, introduction in Annex I in clarifying ESA 2010 10.01). Bottom-up and top-down calculations will only lead to the same result if the level of aggregation is the same.

In all these efforts, the aim is to measure volume (real) economic growth between different periods. Measuring economic growth is a primary objective of economic research. It is not a matter of finding price indicators for flows that, like income, have no actual price and volume dimension.

It is generally not possible to divide income flows into a price and a quantity component and for this reason price and volume measures cannot be defined in the same way as for the flows and stocks of products. Income flows can be measured in real terms only if one chooses some selected basket of goods and services on which the income is typically spent and uses the price index for this basket as a deflator of current incomes (ESA 2010 10.46). The following examples also do not concern a general monetary value adjustment (see Reich 2011).

At EU level, statistics have become very important for the development, implementation and monitoring of EU policies. There is a long history of using results from national accounts (primarily results in current prices) for operational purposes.

Since the establishment of the European Stability and Growth Pact (European Commission 1997) national accounts at constant prices has also gained operational importance. A particular objective of the pact is to avoid excessive budget or excessive public debt burdens. A deficit overshoot is only accepted in the case of difficulties caused by natural disasters or a severe recession. In order to assess the seriousness of the economic recession, the Commission must use national accounts aggregates in real terms for Community policy purposes and, in particular, for the supervision of the Stability and Growth pact (European Commission 1998).

In order to improve the comparability of data for changes in real gross domestic product, the general principles contained in Chapter 10 of the ESA were clarified and further specified in two Commission Decisions (European Commission 1998, 2002). The constant price calculations have to follow the detailed provisions laid down in these two Commission Decisions and in the "Handbook on prices and volume measures in national account" (Eurostat 2016). Havel and Kasberger (2004); Koehler (2006), among others, provide detailed information on the implementation of the provisions in Austria.

The Commission Decision (1998) provides a classification of methods for certain types of 
products into most appropriate methods (A methods), alternatives which may be used if the most appropriate methods cannot be applied (B methods), and methods which shall not be used (C methods).

The minimum level of detail in the measurement of prices and volumes is also laid down in the Commission Decision. The elementary level of aggregation shall be at least as detailed as the P60-level of ESA (European Commission 1998, Principle 1). In order "to derive the most accurate growth rates, the most recent base year possible should be used, since in that case the weights used are most up-to-date, and the problems of disappearance of products and new products are minimised. Together, these considerations lead to the method of deriving the weights always from the previous year" (European Commission 1998, Principle 1.4).

This specification of only seemingly technical details manifests the priority given to analysis over a short period for operational purposes, even to the detriment of other objectives such as the study of structural change over longer periods.

\section{Example 1: Passenger transport}

This example deals with the non-utilisation of season tickets during the pandemic.

\subsection{Situation}

Annual travel passes and similar season tickets entitle the holder to use transport services; in times of a pandemic, this utilisation has decreased significantly, both voluntarily and involuntarily (due to curfews). Season tickets can often be cancelled. Nevertheless, the utilisation of all season tickets issued is considerably lower than under usual circumstances.

\subsection{European legal provisions}

In the area of passenger transport, the Handbook (Eurostat 2016) in section 4.8.1 requires a highly detailed approach, distinguishing both by mode of transport and in terms of the different ways in which services are purchased. Each type of ticket should be seen as a product in its own right, as each ticket entitles the holder to different utilisations under different conditions.

"The output in current prices is essentially equal to the number of tickets sold times the price per ticket, for all different types of tickets. It follows that output in previous year's prices should be equal to the number of tickets sold times the price of each ticket in the previous year. This approach is also followed in the compilation of price indices, where the prices of the different forms of tickets are usually observed and weighted with total sales or purchases of each type of ticket in the base year" (Eurostat 2016, page 89).

These provisions are referred to as the A method, they correspond to the theoretical model and are a manifestation of the economic concept of production in national accounts.

The Handbook (Eurostat 2016) recognises that "in many instances, volume data on the amount of passenger-kilometres produced are available and are used in the national accounts as volume indicators" (Eurostat 2016, page 90). This approach is considered an acceptable B method, although it clearly corresponds to a technical and thus different concept of production than the A method.

\subsection{Treatment in national accounts according to the applicable rules}

The decline in the use of season tickets in the period of the pandemic is reflected - in isolation - in national accounts as follows: 
- At current prices:

- There is no in production, as the season tickets were nevertheless purchased.

- There is no decline in private consumption at current prices, as national accounts record expenditure, not the actual use of goods or services.

- Method A:

- At constant prices and assuming no price changes compared to the previous year when deflating current price results with a producer price index (PPI): No decrease in output at constant prices.

- At constant prices under these conditions: No decline in private consumption of transport services.

- If fewer trains were offered in some phases of the pandemic, this could be taken into account as a quality change in deflation; the result would be a decline in output and private consumption at constant prices.

- In both cases, the result is a reasonable deflator.

- Method B:

- Using volume indicators (amount of passenger-kilometres compared to the previous year) results in a significant decline in production.

- A marked decline in private consumption at constant prices.

- The confrontation of the results of the calculation at current and constant prices leads to a deflator that cannot be seen as an indicator of price change as per the usual way.

Production in the economic context is adequately represented by method $\mathrm{A}$, as is productivity in the economic context (use of resources to achieve an economic result). In terms of a technical concept of production, the measurement in this approach is inadequate; productivity seen as the number of passenger-kilometres performed in relation to the use of resources has clearly decreased. The application of method B is suitable to adequately represent technical production, but leads to surprising results in the system context, since an analogous approach cannot be followed in the calculation at current prices. In contrast to the use of season tickets, there are no problems with the use of single tickets; both the current price and constant price accounts reflect the decline in the use of transport services.

\subsection{Consequences of the European legal provisions}

The concept of the A method requires that the production is to be calculated via the products of the tickets sold by each category and the prices of the respective tickets. In the case of constant price accounting, the prices of the previous year are to be used for this calculation. The Handbook (Eurostat 2016) clearly points out the consequences and the inherent assumptions behind this regulation: "It implies for example, that a kilometre travelled by train on a 'one-off' ticket is a different output than a kilometre travelled on a season ticket. It also implies that a train travelling without passengers still produces output, since season ticket holders have already paid. In this case, output may be seen as not being directly related to the use of the transport service, but as the right of access to it" (Eurostat 2016, page 90).

In this paragraph, a very relevant specification of the concept of production takes place. If, in the case of annual passes and similar tickets, it is the right to use a service that ultimately defines production here, it must be questioned whether production still exists if legal provisions such as curfews in lockdown prohibit users from making use of the services that are offered.

"Volume indicator methods based on passenger-kilometres for passenger transport are B methods, since it has to be assumed that travel habits of the population do not change significantly" 
(Eurostat 2016, page 91). This assumption is probably not longer acceptable in times of a pandemic. However, the Handbook (Eurostat 2016) also argues that "the use of such an indicator typically assumes that only the actual transport of passengers yields output (i.e. an empty train does not produce output)" (Eurostat 2016, page 90). The idea that an empty train produces less than a well-filled train corresponds more to a technical concept of production.

Under normal conditions, the differences in the calculations according to the A method and the B method will yield quite similar results. In times of a pandemic, the results will deviate widely and clearly show that different concepts are operationalised.

Irrespective of the accounting problems made visible by the pandemic, it should be noted: the argumentation of the Handbook with respect to the calculation at constant prices is based on the basic model. "It follows that output in previous year's prices should be equal to the number of tickets sold times the price of each ticket in the previous year" (Eurostat 2016, page 89). Later, however, it states: "The use of appropriate PPIs is an A method. For PPIs to be considered appropriate they would need to cover the various types of tickets available" (Eurostat 2016, page 91). So, the bottom-up argument is made, but the top-down approach is presented as equivalent.

Although the Handbook recognises that transactions are to be taken as the starting point, a partial change of orientation is made in the operationalisation of the theoretical concept.

Value index $=$ Laspeyres volume index $\cdot$ Paasche price index

$=$ Paasche volume index $\cdot$ Laspeyres price index

This repeatedly used representation only applies to the same aggregation levels and ignores everything that happens below the aggregation level of the indices. It also suggests that the operationalisation of the basic concept can only be achieved using indices and that bottom-up and top-down approaches are equivalent.

Quite in contrast to current price accounting, which always operates on actual observed prices at the transaction level, constant price accounting always works with selected prices considered representative at a fundamentally higher level of aggregation. This is particularly true when producer price indices are used. Moreover, hardly any country has producer price indices at their disposal which meet the requirements and use weights according the conditions of the previous year.

In this approach, too, the repeatedly observed contrast between the way of arguing and the convincing rhetoric on the one hand and the actual, recommended approach (what is being measured) on the other hand is clearly visible.

Another aspect deserves attention: Under market conditions, price differences of otherwise very similar goods reflect the different quality or at least the assessment thereof, since there were buyers in the base period who bought the somewhat more expensive goods at the higher prices. However, the large price differentiation with regard to passenger transport services can only be interpreted as differences in quality to a limited extent. Only in the case of expensive airline tickets, it may serve as a quality feature that with such tickets - in contrast to others - rebooking is possible without further costs.

This problem is explicitly addressed in the ESA. If individuals are charged lower fares on condition that they travel only at certain times, typically off-peak times, they are being offered lower-quality transportation since transportation with conditions and transportation without conditions can be considered as different homogeneous products. A shift in the share of such lower (or higher) fares in the aggregate will then be (ideally) treated as a change in volume. If producers charge lower prices to groups of individuals with typically lower incomes, such as pensioners or students, and if such individuals are free to travel at whatever time they choose, this must be treated as price discrimination (ESA 2010 10.16). Consequently, a shift in the share of such lower fares for students or pensioners in the aggregate will not be treated as a change in volume. When interpreting results at constant prices, users need to be aware 
of this convention laid down in the ESA, even if they consider the distinction to be arbitrary to a certain degree.

\section{Example 2: Opera}

This example deals with the limiting audience numbers in the pandemic.

\subsection{Situation}

At the beginning of the 2020/2021 season, the Vienna State Opera (along with many other theatres and concert halls) were allowed to perform, but only in front of 500 instead of 2300 visitors. The organisers refunded the tickets for subscribers who could not attend the performances.

\subsection{European legal provisions}

According to the key aspects outlined in Chapter 4.18.1 of the Handbook (Eurostat 2016), the output of the service is the presentation of the 'performance' to the spectators, the service provided is the personal enjoyment given to the audience by the performance (page 135 Eurostat 2016). "As with provision of transport services, the key principle here is that output should ideally be linked to the number of tickets sold for access to the service, specified by the various types of tickets (so that purchase of a 'season ticket' implies a different service than a one-off ticket)" (Eurostat 2016, page 135).

There is a second important analogy to the situation in public transports. "There may also be a significant subsidy system in operation for some services - for example a museum that grants entry for free (where the basic price is in effect the subsidy per entrant because the subsidies are treated as subsidies on products - see ESA 2010 4.35c)" (Eurostat 2016, page $135)$.

"The A method here for services provided purely to households is to use detailed CPI series adjusted to basic prices as deflators for the value of tickets sold. The method would need to take account of discounted tickets, and any other features that will have a significant influence on quality (for example free programmes or telephone booking)" (Eurostat 2016, page 136).

If we exclude the case that services are provided to businesses, which is also discussed in the Handbook, the B methods are to use the number of tickets sold broken down by type of seat and performance as a volume measure. In the event of ticket data being unavailable, the number of performances could be used as a measure, though this is barely a B method. Any methods which use an insufficient breakdown of product detail, or which use input-based data, are considered $\mathrm{C}$ methods (Eurostat 2016, page 136).

As in the case of passenger transport, the A and B methods differ fundamentally. Method A represents a top-down approach which, when very detailed price indices are available, comes very close to the basic model. Method B is more similar to a bottom-up approach.

\subsection{Treatment in national accounts according to the applicable rules}

- At current prices:

- Massive decline in production, as fewer tickets could be sold than under normal conditions.

- Analogously, massive decline in private consumption, as expenditure is recorded.

- Method A:

- At constant prices using price indices - and assuming no price change - the result is a decrease in output at constant prices equal to that in output at current prices. 
- Deflator $(=1$.

- Method B:

- If the number of tickets sold by ticket category can be weighted with the different prices for each category, a result similar to the one according to method A can be obtained, provided that price information was available in great detail for compiling data according to method A.

If it is assumed that only single tickets were sold (and season tickets are refunded), production at constant prices is adequately represented in the economic context, as is productivity in the economic context (the use of resources to achieve an economic result). The result is a massive decline in productivity.

The different notions of the term output is again present in the text of the Handbook (Eurostat 2016). On the one hand, "output should ideally be linked to the number of tickets sold for access to the service, specified by the various types of tickets" a provision which is clearly consistent with the idea of economic production. On the other hand, there is the phrasing "the output of the service is the presentation of the 'performance' to the spectators" (Eurostat 2016, page 135). This a rather technical view of production or output. In view of this second definition, the approaches offered by method $\mathrm{A}$ and method $\mathrm{B}$ are both inadequate. The performance was presented to the spectators even though few people were present in the audience. Even in front of fewer listeners, all notes were played or sung by the same number of musicians as in normal times; the technical productivity remained constant.

\section{Summary and further considerations}

It can be argued with some justification that the significance of the two examples given for the overall results of national accounts is very small and that the preceding discussion only deals with methodological subtleties.

Nevertheless, some observations of general relevance can be derived. Firstly, it should be noted that two very similar cases are treated very differently in the national accounts under the current rules. The examples essentially differ only in the different way in which the service is paid for. The results of national accounts should reflect the production and use of goods, not the way they are paid for. Should the results of the production measurement of national accounts not be independent of whether single tickets or season tickets are purchased? The differences in the treatment of technically similar services (transport capacity, music), which can or may only be used in a limited way, pose considerable problems for the interpretation of the results and further analyses such as investigations in the changes in productivity.

Secondly, it should be noted that under normal circumstances, alternative approaches (A and B methods) lead to results which are numerically so similar that it does not seem worthwhile to deal with the background of the procedures. This is especially true under the new regime, where the prices of the previous year always have to be used in constant price calculations. Under extraordinary conditions such as a pandemic, it becomes evident that the alternative approaches not only lead to numerically different results, but above all address different issues.

A third aspect of importance: One of the central goals of the European System of National Accounts and the supplementary legal provisions is to ensure a high degree of international comparability. However, different shares of annual tickets in the total number of tickets purchased in different countries lead to very different results of the calculation at constant prices under the current regulations - even despite all other economic circumstances being the same.

In 2019, there were no less than 852300 holders of annual tickets for the Wiener Linien in Vienna (Wiener Stadtwerke 2019), 48 \% of the revenues of the Wiener Linien were accounted 
for by annual tickets in 2019 (Wiener Linien 2019). Analogous problems occur with season tickets at baths, health facilities, cultural and sporting events.

In the pandemic, an immanent and ultimately unresolvable tension becomes more apparent than usual: legal norms are supposed to ensure a very high degree of comparability, while at the same time the principle of subsidiarity allows Member States to choose different methods (adapted to different circumstances).

Terms like appropriate as used in the Commission Decision (European Commission 1998) with respect to methods to be used can only be seen in relation to a well-defined analytical goal. If the rules are defined as conventions that serve to meet the goal of comparability for operational purposes, these terms are acceptable. However, they are massively misleading if they are read to indicate the suitability of the approaches for other analytical goals or even as quality indicators.

The questions raised by the COVID-19 outbreak also highlight the fundamentally different empirical anchoring of the calculations at current prices and the calculations at constant prices. On the model content of national accounts and the types of models to be distinguished, see Richter (2002). Current price accounting is to a large extent a statistical representation of actual economic conditions is also particularly committed to the parsimony principle. "The basic system must continue to reflect and represent as closely as possible economic reality in terms of actual trans-actions and the institutional economic structure in which these occur" (Adler and Sunga 1982, page 56).

The use of the prices of another year results in a model-like representation of the economy, which necessarily eludes direct statistical observation. The accusation of unreality that has sometimes been levelled at the national accounts at constant prices (cf. Neubauer 1974) falls flat insofar as this unreality - this model-like quality - is not a failure of the approach, but intentional. Without a familiarity with the chosen approaches and the underlying assumptions, the interpretation of the results of national accounts is not possible. This is in particular true for national accounts at constant prices.

Last but not least, the discussion indicates that the interest of methodologists and economic researchers should not be limited to what is considered attractive in the academic world such as the choice of an index formula. It would be more relevant to address the analytical concepts and the level of aggregation chosen in the calculations.

The set of central indicators of economic monitoring and further analysis includes overall economic productivity and productivity at the level of individual economic industries. The two examples clearly illustrate how little and how differently the national accounts approaches of measuring production correspond to the concepts of production and productivity with which economists usually argue. They proceed either from a colloquial understanding or from textbook definitions (see Holub and Tappeiner 1988). This discrepancy once again illustrates what Eisner (1989) formulated in a presidential address to the American Economic Association: "Somehow econometricians, theorists, and economic analysts of all stripes have lost essential communication with the compilers and synthesizers of their data. As a consequence, popular discourse, policymaking, and basic principles of economics have suffered inordinate confusion" (Eisner 1989, page 2).

Once again, the question arises as to whether all the different questions can be dealt with adequately by a single system. Official statistics could certainly provide alternative versions in addition to the results adhering to the European legal requirements or at least offer building blocks that would allow economists to create a more suitable data basis for their purposes. Against such a degree of flexibility, it is repeatedly objected that such a policy would put too great a strain on the public, but also many users. This argument addresses the insufficient statistical literacy in general and the unsatisfactory - since not characterised by intensive dialogue - relationship between data producers and data users in economic research (see Griliches 1985; Richter 2013).

The COVID-19 outbreak and the many problems it has raised and made newly visible for 
national accounts could and should be motivation for economists to take a serious look at their data bases, their concepts, processes and model contents. After all, national accounts are the language, the statistical system of macroeconomics (Franz 1994). Only a new familiarity with national accounts can prevent that "in too many instances sophisticated statistical analysis is performed on a data set whose exact meaning and validity are unknown to the author" (Leontief 1971, page 26).

\section{Acknowledgements}

The author is indebted to Norbert Rainer and two anonymous referees for a number of valuable comments and to Marlene Sommer for improving the linguistic quality of the text.

\section{References}

Adler H, Sunga P (1982). "Comments on Richard Ruggles and Nancy Ruggles: Integrated Economic Accounts for the United States, 1947 - 80." Survey of Current Business, 5, 55-57.

Eisner R (1989). "Divergences of Measurement and Theory and Some Implications for Economic Policy." American Economic Review, 79(1), 1-13. doi:10.1177/ 056943459403800201.

European Commission (1997). "Council Regulation (EC) No 1466/97 of 7 July 1997 on the Strengthening of the Surveillance of Budgetary Positions and the Surveillance and Coordination of Economic Policies." Technical Report 1466/97, European Commission. URL https://eur-lex.europa.eu/legal-content/EN/TXT/?uri= CELEX\%3A31997R1466\&qid=1613028641023.

European Commission (1998). "98/715/EC: Commission Decision of 30 November 1998 clarifying Annex a to Council Regulation (EC) No 2223/96 on the European system of national and regional accounts in the Community as concerns the principles for measuring prices and volumes." Technical Report 2223/96, European Commission. Notified under document number C(1998) 3685) (Text with EEA relevance), URL https://eur-lex.europa.eu/ legal-content/EN/TXT/?uri=CELEX\%3A31998D0715\&qid=1613028149303.

European Commission (2002). "2002/990/EC: Commission Decision of 17 December 2002 further clarifying Annex A to Council Regulation (EC) No 2223/96 as concerns the principles for measuring prices and volumes in national accounts." Technical Report 2223/96, European Commission. Text with EEA relevance (notified under document number C(2002) 5054), URL https://eur-lex.europa.eu/legal-content/EN/TXT/?uri= CELEX\%3A32002D0990\&qid=1613028417417.

Eurostat (2013). "European System of Accounts ESA 2010." Technical Report KS-02-13-269$E N-C$, Eurostat. doi:10.2785/16644. Theme: Economy and Finance Collection: Manual and guidelines.

Eurostat (2016). "Handbook on Prices and Volume Measures in National Accounts - 2016 Edition." Technical Report KS-GQ-14-005-EN-, Eurostat. doi:10.2785/53279. Theme 2: Economy and finance Collection: Manuals and guidelines.

Eurostat (2021). "Guidelines and Methodological Notes in the Context of the COVID-19 Crisis." Technical report, Eurostat. URL https://ec.europa.eu/eurostat/en/data/ metadata/covid-19-suppor-for-statisticians.

Franz A (1988). "Tschernobyl: Fernwirkungen in der Volkseinkommensrechnung." Der öffentliche Sektor, pp. 1-15. 
Franz A (1994). Volkswirtschaftliche Gesamtrechnungen: Das Statistische System der Makroökonomie. Österreichische Studien zur Amtlichen Statistik, ÖSTAT.

Griliches Z (1985). "Data and Econometricians - The Uneasy Alliance." American Economic Review, 75(2), 196-200.

Havel U, Kasberger F (2004). "Einführung der Vorjahrespreisbasis und Verkettung in der Österreichischen VGR." Statistische Nachrichten, 8, 790-795.

Holub H, Tappeiner G (1988). "Schwierigkeiten und Fallen beim Umgang mit volkswirtschaftlichen Begriffen." Wirtschaftswissenschaftliches Studium, 17(8), 422-426.

Koehler B (2006). "Volkswirtschaftliche Gesamtrechnungen: Preis- und Volumenmessung im Gesundheitsbereich." Statistische Nachrichten, 4, 295-300.

Leontief W (1971). "Theoretical Assumptions and Nonobserved Facts." American Economic Review, 61(1), 1-7.

Neubauer W (1974). "Irreales Inlandsprodukt in konstanten Preise. Kritisches zur Deflationierung in der Volkswirtschaftlichen Gesamtrechnung." Wirtschafts- und Sozialstatistisches Archiv, 3, 237-271.

Reich U (2011). "Additive Zerlegung der Bewegung der Bruttowertschöpfung - ein Vergleich zweier Wachstumsperioden." Wirtschafts- und Sozialstatistisches Archiv, 4, 317-346. doi: $10.1007 / \mathrm{s} 11943-010-0090-y$.

Richter J (2002). Kategorien und Grenzen der empirischen Verankerung der Wirtschaftsforschung. Lucius \& Lucius. ISBN 3-8282-0224-1.

Richter J (2013). "Empirical Economics and Economic Data Some Remarks on an Uneasy Relationship." In R Bardazzi (ed.), Economic Multisectoral Modelling between Past and Future : A Tribute to Maurizio Grassini and a Selection of his Writings, pp. 151-175. Firenze University Press. ISBN 978-88-6655-409-7.

Wiener Linien (2019). "Geschäftsbericht 2019." Accessed on 2021-01-25, URL https: //www.wienerstadtwerke. at/eportal3/ep/contentView.do/pageTypeId/71283/ programId/3600056/contentTypeId/1001/channelId/-49476/contentId/5001347.

Wiener Stadtwerke (2019). "Zahlen \& Fakten; Betriebsangaben 2019." Accessed on 202101-25, URL https://www.wienerlinien.at/media/files/2020/wl_betriebsangaben_ 2019_deutsch_358274.pdf.

\section{Affiliation:}

Josef Richter

Windschutzstr. 14

1140 Wien, Austria

E-mail: josef.richter@aon.at

\section{Austrian Journal of Statistics}

published by the Austrian Society of Statistics

Volume 50

July 2021 http://www.ajs.or.at/

http://www.osg.or.at/

Submitted: 2021-01-25

Accepted: 2021-02-21 